\title{
Gender Differences in the Association between Childhood Socioeconomic Status and Cognitive Function in Later Life
}

\author{
Jiyoung Lyu \\ National Institute of Dementia, Seongnam 463-400, Republic of Korea \\ Correspondence should be addressed to Jiyoung Lyu; jyyoo200@nid.or.kr
}

Received 28 August 2015; Revised 17 November 2015; Accepted 26 November 2015

Academic Editor: Ian Stuart-Hamilton

Copyright (C) 2015 Jiyoung Lyu. This is an open access article distributed under the Creative Commons Attribution License, which permits unrestricted use, distribution, and reproduction in any medium, provided the original work is properly cited.

Objectives. This study was aimed to explore the gender differences in the association between childhood socioeconomic status (SES) and cognitive function in later life. Methods. Using a nationally representative sample from the Health and Retirement Study, 5,544 females and 3,863 males were analyzed separately. Growth curve models were used to examine memory status and change in memory from 1998 to 2010. Results. The results showed that SES disadvantage in childhood was associated with lower memory at baseline controlling for adult SES and other covariates. In addition, cumulated disadvantage in SES was associated with poor memory in both genders. Statistically, the impact of cumulative SES on memory function at baseline was significantly different by gender. Discussion. These findings suggest that childhood SES has long-term effects on cognitive function among both men and women, and cumulative SES from childhood to adulthood may be more important for men than women with respect to their memory performance.

\section{Introduction}

With the growing interest in cognitive health in later life, many studies have examined the factors related to cognition among older adults. Through the capacity of longitudinal studies, researchers were able to examine the relationship between adult health outcomes and circumstances from earlier stages of the life course [1]. Many previous studies used a variety of childhood socioeconomic status (SES) indicators to examine the relationship between childhood SES and cognition in later life [2-13]. Consistently, findings suggested that disadvantages in childhood SES is strongly associated with poor cognitive function in later life.

Theoretically, the life course perspective provides a view of the aging process from birth to death [14]. In life course epidemiology, the long-term relationships between early life exposure and social and economic deprivation with later life health disparities are often examined [15]. Early childhood events or conditions are often found to have long-term effects on later health outcomes regardless of any other experiences during the life cycle $[15,16]$. In addition, some risk exposures are accumulated over the life course $[1,15,17]$. According to
Graham [17], disadvantage at different time periods can have a cumulative effect on later health outcomes.

Previous studies have also shown that there are gender differences in later health outcomes [18-21]. In terms of having different structural, behavioral, and psychosocial characteristics related to health outcomes by gender, gender differences in the relationship between health problems and cognitive well-being are not surprising [19]. Given gender differences in educational, employment, and income opportunities along with other gender-based experiences throughout the life course, the association between childhood and adult SES and cognitive change might be different for different gender groups. However, evidences lack examining gender differences in the above associations longitudinally.

Therefore, the purpose of this study is to examine the gender differences in the impact of childhood and adult SES on cognitive health observed over 12 years among a sample of older adults in the United States. Nationally representative longitudinal data from the 1998 to 2010 Health and Retirement Study (HRS) are examined using growth curve models. This study explores specific measure of cognitive function such as memory, since memory function has been found 
to be a sensitive measure of cognitive change in later life [22]. Specifically, memory function related to acquiring new information is associated with change in the hippocampal structure of the brain, which in turn is an early sign of Alzheimer's disease [22]. This study addresses the following research questions:

(1) Is the association between childhood SES, adult SES, and memory moderated by gender?

(2) Is the association between cumulative SES and memory moderated by gender?

\section{Materials and Methods}

2.1. Data Source. Data for this study were taken from the Health and Retirement Study (HRS), a nationally representative survey of persons aged 51 and older conducted by the University of Michigan and funded by the National Institute on Aging. The HRS was a biennial longitudinal panel study of community-dwelling adults in the United States, with oversamples of African Americans and Hispanics [23]. The HRS provided detailed information on income and wealth, work, pension plans, health insurance, disability, physical health and functioning, cognitive functioning, and health care expenditures. Additional information about the survey may be found at http://hrsonline.isr.umich.edu/. The childhood SES questionnaire items were included in the HRS survey beginning in 1998. This study used the seven waves from the core HRS data (1998-2010). Data on household income and parent's education were taken from special HRS data files constructed and distributed by the RAND Corporation [24].

2.2. Study Sample. There were 21,384 HRS respondents in 1998. The study sample was restricted to respondents living in the community. The sample included individuals who were aged 65 and over at baseline because cognition is more likely to decline after age 65 [25]. These restrictions reduced the sample to 11,126 respondents. The measures of cognitive functioning were derived from self-reported responses to a battery of questionnaire items. Thus, proxy-respondents were excluded, reducing the sample size to 9,829 respondents at baseline. Respondents whose race was reported as other than White or Black were recorded as "other race" in the HRS data file: these respondents were excluded from the study sample due to small sample size, reducing the sample to 9,663 respondents. Respondents with missing data on the other variables were also excluded at baseline $(n=256$ or $2.6 \%$ of eligible respondents). After listwise deletion of respondents with missing data on the remaining variables, the final study sample included 9,407 respondents at baseline (5,544 respondents for females and 3,863 respondents for males).

The number of observations decreased during the 12-year period due to sample attrition following baseline. Fortunately, one of the advantages of growth curve models is that the technique allowed for the analysis of cases with incomplete data, maximizing the amount of information available for the analysis. A total of 42,500 person-wave observations were included in the analyses over the seven waves from 1998 to 2010 (25,609 observations for females and 16,891 observations for males).

\subsection{Measures}

2.3.1. Dependent Variable. The measure of cognitive functioning was derived from a self-reported cognition questionnaire [20]. A memory scale was comprised of two items: immediate free recall (10 points) and delayed free recall (10 points). Immediate free recall and delayed free recall tests assess the respondent's short-term memory [25]. The interviewer reads a list of 10 nouns and the respondent is asked to recall as many words as possible from the list in any order (immediate free recall). After about 5 minutes of asking other questions, the respondent is asked to recall the words from the immediate free recall task (delayed free recall). The total memory score of word recall was included in the analyses (range: 0-20).

2.3.2. Independent Variables. Childhood SES was ascertained with four retrospective questionnaire items: father's education, mother's education, father's occupation, and family financial well-being during childhood [8]. Father's education and mother's education variables were based on a set of dichotomous measures from respondent's self-report of parent's educational attainment (eight or more years of education (reference), less than eight years of education, and missing). Respondents with missing values represented $15.4 \%$ of the sample for father's education and $12.4 \%$ for mother's education; approximately $50 \%$ of these missing cases were the result of one or both parents not living with the respondent during childhood (due to death or other reasons). Rather than exclude these cases, a dichotomous variable was introduced identifying this form of item nonresponse. Three dichotomous variables were created for father's occupation when the respondent was 16 years old (white-collar job (reference), blue-collar job, and missing). White-collar occupations included managers, professionals, salesmen, and clerical and service jobs. Blue-collar occupations included all other types of jobs. A set of dichotomous variables capturing financial well-being during childhood was based on a question asking respondents to rate their financial wellbeing from birth to age 16 (poor (reference), about average, and pretty well-off) [8]. Although there are other childhood SES indicators in the HRS data file, this study included the above four items to be consistent with the available adult SES measures, to compare with previous research, and to allow for the estimation of a cumulative SES measure (see below).

Adult SES was identified using respondent's education and annual household income. Education was measured based on years of education completed at baseline (range 0$17+$ ). Household income was transformed with the natural log because the distribution is positively skewed. Missing income data were imputed by RAND [24]. Although wealth is a marker of SES among older adults, we estimated models using the household income variable to be consistent with the most common approach in the research literature. In a sensitivity 
analysis, we estimated models that also included wealth, and the results were consistent with what we found with household income. For parsimony, we decided to include only household income.

Cumulative SES was measured with an index that combined childhood SES variables with respondent's education, and household income at baseline [8]. The first step was to create a childhood SES index based on the average of the four childhood SES items for each respondent: father's education, mother's education, father's occupation, and financial wellbeing at childhood. The index included measures of parent's education ( $1=8$ or more years of education; $0=$ otherwise), father's occupation ( $1=$ white-collar occupation; $0=$ otherwise), and financial well-being at childhood ( $1=$ average or well-off; 0 = poor). Respondents who had missing data on parent's education and father's occupation were coded as 0 based on preliminary analyses showing that respondents in this category had similar characteristics with respondents in the lowest category [8]. After the childhood SES index was created, it was dichotomized at the median ( $1=$ above median; $0=$ at or below the median). Although the use of a binary categorization of the childhood SES index may result in a loss of the indicator's sensitivity for identifying variability in the characterization of SES, the childhood SES index was dichotomized in order to be consistent with the other measures generated for the cumulative SES index. The next step was to generate adult SES measures for the cumulative SES index. Respondent's education was dichotomized at the college level ( $1=$ attended at least some college; $0=$ otherwise), and respondent's household income was dichotomized at the median $(1=$ above the median sample value; $0=$ at or below the median) [8]. Finally, the childhood SES index and the revised measures of adult SES were combined into a cumulative SES index that ranged from 0 to 3 (higher scores indicating greater advantage over the life course).

2.3.3. Covariates. Race and ethnicity were combined to create a set of dichotomous variables, including non-Hispanic White (reference), non-Hispanic Black, and Hispanic. Marital status was coded as a set of dichotomous variables, including married (reference), divorced/separated, widowed, and never married.

Self-reported childhood health was included to provide an indicator of early life health. This variable was dichotomized as $1=$ good/fair/poor and $0=$ very good/excellent. Self-rated health was dichotomized as $1=$ fair/poor and 0 = good/very good/excellent. The slight difference in the cutpoints chosen for the self-rated childhood and adult health variables was based on inspection of the distribution of cases in each category of the original measures.

Disability status was measured with limitations in Activities of Daily Living (ADL) and Instrumental Activities of Daily Living (IADL). ADL items included dressing, walking, bathing, eating, getting in or out of bed, and toileting. IADL items included preparing hot meals, grocery shopping, making telephone calls, taking medications, and managing money. Each item was coded as 1 if respondents reported difficulty engaging in the activity, or answered either "cannot do" or "do not do" because of a health or memory problem. The total number of difficulties reported was used to construct the disability measures (ADL: range 0-6 and IADL: range $0-5)$. Depression was measured using eight items from the Center for Epidemiological Studies Depression (CESD) scale [26]. Respondents were asked whether they had depressive symptoms during the past week $(1=$ yes; $0=$ no). Two items ("feel happy" and "enjoyed life") were reverse coded to be consistent with the other indicators. The total number of depressive symptoms was used as a depression measure (range 0-8): internal consistency (Cronbach's $\alpha$ ) was .744 at baseline. A measure of chronic health conditions was created by summing the number of major conditions for which respondents were diagnosed: high blood pressure, diabetes, cancer, lung disease, heart disease, stroke, psychiatric problems, and arthritis (range 0-8).

Smoking status was coded with a set of dichotomous variables based on two questions "Have you ever smoked cigarettes?" and "Do you smoke cigarettes now?" (never smoked, former smoker, and current smoker (reference)). Drinking status was coded as a set of dichotomous variables based on the number of alcoholic drinks per day (never drinks, moderate drinker (reference), and heavy drinker), where moderate consumption was defined as having up to one drink per day for women and up to two drinks per day for men [27]. Physical activity was dichotomized based on the frequency of engaging in vigorous exercise $(1=$ one or more times a week; $0=$ otherwise).

2.4. Analytic Strategy. Descriptive statistics for each gender are presented at baseline for all of the variables used in the analysis. $t$-test and chi-square test were conducted to evaluate the gender differences in descriptive statistics. Growth curve models were then estimated separately for each gender to examine the relationship between the SES variables and cognition over time, along with the set of covariates identified above. Statistical gender differences in the above associations were also evaluated.

Growth curve modeling is designed to analyze the trajectory of repeated measures in longitudinal data [28]. The growth curve models parameterized within-person (level 1) and between-person (level 2) variability in cognition at baseline and over time. The "time" variable for this study was chronological age because cognition change is more closely related to age than the more arbitrary survey interview cycle. Age was centered at the sample mean. The mean age at baseline was 75 years old; thus, model intercepts represent the average memory score at age 75 . Childhood SES factors, respondent's education, cumulative SES index, childhood health, and race/ethnicity variables were included in the models as time-invariant factors. All other covariates were treated as time-varying factors. Time-varying continuous covariates were centered at their sample means.

Model parameters were estimated with the full information maximum likelihood method using SAS PROC MIXED (9.3). The maximum likelihood method used all of 
TABLE 1: Descriptive statistics for the study sample at baseline by gender.

\begin{tabular}{|c|c|c|c|c|c|}
\hline \multirow{2}{*}{ Variables } & \multicolumn{2}{|c|}{ Female $(N=5,544)$} & \multicolumn{2}{|c|}{ Male $(N=3,863)$} & \multirow{2}{*}{$p$ value } \\
\hline & Mean $(\%)$ & SD & Mean (\%) & SD & \\
\hline \multicolumn{6}{|l|}{ Dependent variable } \\
\hline Total memory score (range: $0-20$ ) & 9.2 & 3.96 & 8.5 & 3.67 & $* * *$ \\
\hline \multicolumn{6}{|l|}{ Independent variable } \\
\hline Father's education (high) ${ }^{\mathrm{a}}$ & $48.5 \%$ & & $52.5 \%$ & & $* * *$ \\
\hline Father's education (low) & $35.1 \%$ & & $33.5 \%$ & & \\
\hline Father's education (missing) & $16.4 \%$ & & $13.9 \%$ & & \\
\hline Mother's education (high) ${ }^{\mathrm{a}}$ & $55.0 \%$ & & $59.8 \%$ & & $* * *$ \\
\hline Mother's education (low) & $32.1 \%$ & & $28.5 \%$ & & \\
\hline Mother's education (missing) & $12.9 \%$ & & $11.8 \%$ & & \\
\hline Father's occupation (white-collar) ${ }^{\mathrm{a}}$ & $19.8 \%$ & & $21.4 \%$ & & $* * *$ \\
\hline Father's occupation (blue-collar) & $64.9 \%$ & & $66.9 \%$ & & \\
\hline Father's occupation (missing) & $15.3 \%$ & & $11.7 \%$ & & \\
\hline Financial well-being during childhood (poor) ${ }^{\mathrm{a}}$ & $32.3 \%$ & & $37.7 \%$ & & $* * *$ \\
\hline Financial well-being during childhood (average) & $62.3 \%$ & & $55.8 \%$ & & \\
\hline Financial well-being during childhood (well-off) & $5.4 \%$ & & $6.5 \%$ & & \\
\hline Respondent's education (in years) & 11.6 & 3.21 & 11.9 & 3.65 & $* * *$ \\
\hline Respondent's household income (logged) & 9.9 & 1.03 & 10.3 & 0.91 & $* * *$ \\
\hline Cumulative SES index (range: 0-3) & 1.0 & 1.01 & 1.2 & 1.06 & $* * *$ \\
\hline \multicolumn{6}{|l|}{ Covariates } \\
\hline Race/ethnicity (non-Hispanic white) ${ }^{\mathrm{a}}$ & $81.1 \%$ & & $83.3 \%$ & & $*$ \\
\hline Race/ethnicity (non-Hispanic black) & $12.9 \%$ & & $11.0 \%$ & & \\
\hline Race/Ethnicity (Hispanic) & $6.1 \%$ & & $5.8 \%$ & & \\
\hline Marital status (married) $)^{\mathrm{a}}$ & $46.0 \%$ & & $77.9 \%$ & & $* * *$ \\
\hline Marital status (divorced/separated) & $8.0 \%$ & & $6.2 \%$ & & \\
\hline Marital status (widowed) & $43.1 \%$ & & $13.3 \%$ & & \\
\hline Marital status (never married) & $2.8 \%$ & & $2.7 \%$ & & \\
\hline Childhood health (good/fair/poor) & $27.3 \%$ & & $25.6 \%$ & & \\
\hline Self-rated health (fair/poor) & $34.4 \%$ & & $33.4 \%$ & & \\
\hline ADL (range: 0-6) & 0.5 & 1.12 & 0.3 & 0.96 & $* * *$ \\
\hline IADL (range: $0-5$ ) & 0.3 & 0.85 & 0.2 & 0.68 & $* * *$ \\
\hline Depression (range: $0-8$ ) & 1.8 & 1.97 & 1.4 & 1.76 & $* * *$ \\
\hline Chronic health conditions (range: $0-8$ ) & 1.9 & 1.33 & 1.8 & 1.32 & $*$ \\
\hline Smoking status (never smoker) & $55.9 \%$ & & $25.0 \%$ & & $* * *$ \\
\hline Smoking status (former smoker) & $34.3 \%$ & & $63.5 \%$ & & \\
\hline Smoking status (current smoker) ${ }^{\mathrm{a}}$ & $9.7 \%$ & & $11.5 \%$ & & \\
\hline Drinking status (never drinker) & $62.8 \%$ & & $45.8 \%$ & & $* * *$ \\
\hline Drinking status (moderate drinker) ${ }^{\mathrm{a}}$ & $30.5 \%$ & & $46.0 \%$ & & \\
\hline Drinking status (heavy drinker) & $6.7 \%$ & & $8.2 \%$ & & \\
\hline Physical activity & $35.2 \%$ & & $44.6 \%$ & & $* * *$ \\
\hline
\end{tabular}

${ }^{\mathrm{a}}$ Reference group in regression models.

${ }^{*} p<.05,{ }^{* *} p<.01$, and ${ }^{* * *} p<.001$.

the observed data [28]. Although missing data due to sample attrition occurred during the observation period, incomplete (unbalanced) data were evaluated effectively in these growth curve models, reducing the biasing effects associated with this form of missingness. Both fixed effects and random effects components are presented [28].

\section{Results}

3.1. Descriptive Statistics by Gender. Table 1 included descriptive statistics for the subsamples defined by gender. When comparing females and males, women $(\mathrm{M}=9.2, \mathrm{SD}=$ 3.96) had significantly higher total memory scores than men 
TABLE 2: Growth curve model estimates for childhood SES, adult SES, and total memory score by gender.

\begin{tabular}{|c|c|c|c|}
\hline & $\begin{array}{c}\text { Female } \\
\text { Estimate (SE) }\end{array}$ & $\begin{array}{c}\text { Male } \\
\text { Estimate (SE) }\end{array}$ & $\begin{array}{c}t \text {-statistics } \\
p \text { value }\end{array}$ \\
\hline \multicolumn{4}{|l|}{ Fixed effects } \\
\hline Intercept (at age 75) & $9.558(0.155)^{* * *}$ & $8.021(0.170)^{* * *}$ & $* * *$ \\
\hline Father's education (low) & $-0.050(0.089)$ & $0.047(0.101)$ & \\
\hline Father's education (missing) & $-0.028(0.115)$ & $0.102(0.148)$ & \\
\hline Mother's education (low) & $-0.178(0.090)^{*}$ & $-0.142(0.105)$ & \\
\hline Mother's education (missing) & $-0.355(0.122)^{* *}$ & $-0.273(0.148)$ & \\
\hline Father's occupation (blue-collar) & $-0.147(0.088)$ & $-0.369(0.100)^{* * *}$ & \\
\hline Father's occupation (missing) & $-0.168(0.118)$ & $-0.192(0.146)$ & \\
\hline Childhood financial status (average) & $-0.240(0.072)^{* * *}$ & $-0.203(0.081)^{*}$ & \\
\hline Childhood financial status (well-off) & $-0.273(0.156)$ & $-0.334(0.164)^{*}$ & \\
\hline Respondent's education & $0.197(0.013)^{* * *}$ & $0.217(0.013)^{* * *}$ & \\
\hline Respondent's household income & $0.123(0.025)^{* * *}$ & $0.203(0.032)^{* * *}$ & \\
\hline Age & $-0.148(0.014)^{* * *}$ & $-0.108(0.017)^{* * *}$ & \\
\hline Father's education (low) $*$ age & $0.016(0.012)$ & $-0.009(0.015)$ & \\
\hline Father's education (missing) $*$ age & $0.028(0.016)$ & $0.009(0.023)$ & \\
\hline Mother's education (low) $*$ age & $-0.019(0.012)$ & $0.009(0.015)$ & \\
\hline Mother's education (missing) $*$ age & $-0.036(0.017)^{*}$ & $-0.017(0.022)$ & \\
\hline Father's occupation (blue-collar) $*$ age & $-0.001(0.012)$ & $-0.014(0.015)$ & \\
\hline Father's occupation (missing) $*$ age & $0.007(0.016)$ & $-0.013(0.021)$ & \\
\hline Childhood financial status (average) $*$ age & $-0.004(0.010)$ & $-0.017(0.012)$ & \\
\hline Childhood financial status (well-off) $*$ age & $-0.027(0.021)$ & $-0.052(0.024)^{*}$ & \\
\hline Respondent's education $*$ age & $-0.006(0.002)^{* * *}$ & $-0.007(0.002)^{* * *}$ & \\
\hline Respondent's household income $*$ age & $0.000(0.003)$ & $0.006(0.005)$ & \\
\hline \multicolumn{4}{|l|}{ Random effects } \\
\hline Between-person variation & $3.715(0.111)^{* * *}$ & $3.374(0.122)^{* * *}$ & \\
\hline Covariance & $-0.008(0.008)$ & $-0.010(0.009)$ & \\
\hline Linear change & $0.000(0.000)$ & $0.000(0.000)$ & \\
\hline Within-person variation & $6.622(0.067)^{* * *}$ & $5.510(0.069)^{* * *}$ & \\
\hline \multicolumn{4}{|l|}{ Pseudo $R$-square } \\
\hline Level-1 (within-person) & .090 & .073 & \\
\hline Level-2 (between-person) & .234 & .286 & \\
\hline
\end{tabular}

Adjusted for all covariates.

${ }^{*} p<.05,{ }^{* *} p<.01$, and ${ }^{* * *} p<.001$.

$(\mathrm{M}=8.5, \mathrm{SD}=3.67)(p<.001)$. Female respondents reported that $48.5 \%$ of their fathers were highly educated, while males reported that $52.5 \%$ of their fathers were highly educated $(p<.001)$. In addition, women reported that $55.0 \%$ of their mothers were highly educated, while men reported that $59.8 \%$ of their mothers were highly educated $(p<.001)$. In terms of father's occupation, $19.8 \%$ of women and $21.4 \%$ of men reported that their fathers had a white collar job $(p<.001)$. About $32.3 \%$ of women and $37.7 \%$ of men reported that their financial status at childhood was poor $(p<.001)$. Education $(p<.001)$, income $(p<.001)$, and cumulative SES levels $(p<.001)$ were lower among females than males.

3.2. Growth Curve Model Results: Childhood SES, Adult SES, and Memory. Table 2 included results from growth curve models by gender, with differences evaluated with $t$-statistics. Here, the results are shown for the fully adjusted model to examine gender differences in the relationship between childhood SES and total memory scores controlling for adult SES and other covariates. The results showed that the mean total memory score at age 75 was $9.558(p<.001)$ for women and $8.021(p<.001)$ for men. Differences in parameter estimates were tested with $t$-statistics and showed that there was a statistically significant gender difference in the mean total memory score at age $75(p<.001)$. Total memory scores decreased with each year of age by $0.148(p<.001)$ for women and $0.108(p<.001)$ for men. However, there was no gender difference in this association.

For only female group, respondents who had missing values on mother's education had steeper rate of change in total memory scores than those who had a mother with a high education $(-0.036, p<.05)$. In addition, female respondents who had a mother with a low education $(-0.178$, $p<.05)$ and who had missing values on mother's education 
TABLE 3: Growth curve model estimates for cumulative SES and total memory score by gender.

\begin{tabular}{|c|c|c|c|}
\hline & $\begin{array}{c}\text { Female } \\
\text { Estimate (SE) }\end{array}$ & $\begin{array}{c}\text { Male } \\
\text { Estimate (SE) }\end{array}$ & $\begin{array}{c}t \text {-statistics } \\
p \text { value }\end{array}$ \\
\hline \multicolumn{4}{|l|}{ Fixed effects } \\
\hline Intercept (at age 75) & $9.275(0.126)^{* * *}$ & $7.659(0.135)^{* * *}$ & $* * *$ \\
\hline Cumulative SES & $0.424(0.035)^{* * *}$ & $0.584(0.040)^{* * *}$ & $* *$ \\
\hline Age & $-0.160(0.005)^{* * *}$ & $-0.135(0.006)^{* * *}$ & $* *$ \\
\hline Cumulative SES $*$ age & $-0.008(0.005)$ & $-0.012(0.006)^{*}$ & \\
\hline \multicolumn{4}{|l|}{ Sociodemographic factors } \\
\hline Non-Hispanic black & $-1.261(0.101)^{* * *}$ & $-0.966(0.128)^{* * *}$ & \\
\hline Hispanic & $-1.125(0.140)^{* * *}$ & $-0.997(0.168)^{* * *}$ & \\
\hline Divorced/separated & $0.028(0.106)$ & $0.085(0.137)$ & \\
\hline Widowed & $-0.306(0.057)^{* * *}$ & $-0.348(0.078)^{* * *}$ & \\
\hline Never married & $-0.369(0.189)$ & $-0.374(0.225)$ & \\
\hline \multicolumn{4}{|l|}{ Health factors } \\
\hline Childhood health (good/fair/poor) & $-0.140(0.075)$ & $-0.206(0.088)^{*}$ & \\
\hline Self-rated health (fair/poor) & $-0.163(0.050)^{* *}$ & $-0.110(0.056)^{*}$ & \\
\hline Number of ADLs & $-0.030(0.023)$ & $-0.101(0.029)^{* * *}$ & \\
\hline Number of IADLs & $-0.617(0.027)^{* * *}$ & $-0.475(0.036)^{* * *}$ & $* *$ \\
\hline Number of depressive symptoms & $-0.010(0.012)$ & $-0.026(0.015)$ & \\
\hline Number of chronic health conditions & $-0.326(0.020)^{* * *}$ & $-0.291(0.022)^{* * *}$ & \\
\hline \multicolumn{4}{|l|}{ Health behaviors } \\
\hline Never smoker & $-0.391(0.107)^{* * *}$ & $-0.015(0.129)$ & \\
\hline Former smoker & $-0.339(0.102)^{* * *}$ & $-0.038(0.108)$ & \\
\hline Never drinker & $-0.348(0.052)^{* * *}$ & $-0.361(0.056)^{* * *}$ & \\
\hline Heavy drinker & $-0.050(0.092)$ & $0.078(0.099)$ & \\
\hline Engaging in physical activity & $0.576(0.045)^{* * *}$ & $0.514(0.047)^{* * *}$ & \\
\hline \multicolumn{4}{|l|}{ Random effects } \\
\hline Between-person variation & $3.998(0.117)^{* * *}$ & $3.751(0.131)^{* * *}$ & \\
\hline Covariance & $-0.009(0.008)$ & $-0.015(0.010)$ & \\
\hline Linear change & $0.000(0.000)$ & $0.000(0.000)$ & \\
\hline Within-person variation & $6.622(0.067)^{* * *}$ & $5.512(0.069)^{* * *}$ & \\
\hline \multicolumn{4}{|l|}{ Pseudo $R$-square } \\
\hline Level-1 (within-person) & .090 & .073 & \\
\hline Level-2 (between-person) & .179 & .210 & \\
\hline
\end{tabular}

$(-0.355, p<.01)$ had lower total memory scores than those who had a mother with a high education. In contrast, compared to people whose father had a white-collar job, people whose father had a blue-collar job had lower total memory scores only among male group $(-0.369, p<.001)$. In terms of financial status during childhood, having average financial status during childhood was negatively associated with total memory scores for both groups $(-0.240, p<$ .001 for females; $-0.203, p<.05$ for males). Only among male group, respondents who had well-off financial status during childhood had lower total memory scores $(-0.334$, $p<.05)$ as well as steeper decline in total memory score $(-0.052, p<.05)$ than respondents who had poor financial status during childhood. Respondent's education $(0.197, p<$ .001 for females; $0.217, p<.001$ for males) and household income $(0.123, p<.001$ for females; $0.203, p<.001$ for males) were positively associated with total memory scores for both gender groups. In addition, respondent's education was significantly associated with change in memory scores for both gender groups $(-0.006, p<.001$ for females; -0.007 , $p<.001$ for males).

3.3. Growth Curve Model Results: Cumulative SES and Memory. Table 3 included results from growth curve models by gender when cumulative SES index was used in the analyses. The results showed that the mean total memory score at age 75 was $9.275(p<.001)$ for women and $7.659(p<.001)$ for men. Differences in parameter estimates were tested with $t$-statistics and showed that there was a significant gender difference in the mean total memory score at age $75(p<$ $.001)$. The total memory score decreased with each year of age by $0.160(p<.001)$ for women and $0.135(p<.001)$ for men. Also, this association was significantly different by gender $(p<.01)$. For both female and male groups, respondents 
with better cumulative SES had higher total memory scores (0.424, $p<.001$ for females; $0.584, p<.001$ for males), and this association was also significantly different by gender $(p<$ $.01)$. Respondents with better cumulative SES had steeper change in total memory score only among men $(-0.012, p<$ $.05)$.

\section{Discussion}

The purpose of this study was to examine the gender differences in the relationships among childhood and adult SES indicators and the level and change in total memory function among older adults, using a nationally representative longitudinal sample from the Health and Retirement Study (HRS) over 12 years (1998 to 2010). The association between childhood SES indicators, adult SES indicators, and memory performance and the relationship between cumulated SES from childhood to adulthood and memory performance were examined by each gender.

First, gender differences in the relationship between childhood SES, adult SES, and memory function were examined. Results showed that women had significantly higher memory than men at age 75, which supports previous findings [20]. However, no statistically significant gender differences were found for the relationship between SES factors and memory. This result suggests that gender differences in memory function may not be explained by each SES factor.

However, gender differences in the relationship between cumulative SES and memory function were examined. Women had significantly higher memory than men at age 75 , and the rate of decline in memory was stronger for women than for men. In addition, the relationship between cumulative SES and memory was significantly different by gender. For example, compared to women who had high cumulative SES, men who had high cumulative SES had higher memory scores. This result suggests that cumulated SES from childhood to adulthood is more important for men than women with respect to their memory performance.

There are several limitations to this study that should be noted. First, cognitive function was measured only among self-respondents. Since proxy reports are often used for respondents who have severe cognitive impairment, there might be selection bias related to having relatively healthy individuals in the study sample. There is a chance that some potential respondents who were disadvantaged in childhood might have been excluded from the study because of poor cognitive health. Second, the childhood measures were selfreported retrospective measures. Although relatively objective measures such as parents' education and occupation seem reliable, measures such as childhood health or financial well-being at childhood are more subjective. For example, people who grew up in the Great Depression era may subjectively believe their families were less well-off because of the general economic climate even though they were well-off compared to others. Therefore, there might be a recall bias in this measure and the accuracy of the measure is in question. Third, several biological, psychosocial, and behavioral factors that might have effect on cognitive performance were not included in this study [29-31]. In HRS, psychosocial leavebehind questionnaires were given to participants beginning in 2004, including detailed indicators of social participation, social support, sense of control, and stressful life events [32]. Since the purpose of this study was to examine the cognitive trajectory of participants from 1998 to 2010, these additional measures were not assessed. Finally, although early education may have more effect on cognitive development than later education, this study could not adjust for this difference. Since many older adults get lifetime education, examining early education differently from later education will be beneficial to develop strategies to enhance memory performance in later life. Further studies will be needed to investigate this issue.

Despite these limitations, this study adds to the scientific literature in several ways. First, using a longitudinal sample from the HRS, this study examined cognition trajectories over 12 years. Using a growth curve modeling technique, this study analyzed the full sample of available respondents regardless of attrition following the baseline observation. Second, analyzing a large sample and nationally representative data, the study results are generalizable. In addition, taking advantage of this large dataset, the study was able to examine gender differences. Therefore, interventions considering gender differences can be designed and implemented to enhance cognitive health in later life.

\section{Conclusions}

Childhood SES has long-term effects on cognitive status as well as for cognitive change in later life in both gender groups. Study results indicate that cognition in later life is the result of a complex set of circumstance both early and later in adult life. In addition, gender differences in the relationship between cumulative SES and cognitive function were affirmed. Moreover, it should be noted that individual childhood SES indicators have different impacts on cognitive function by each gender, and there still remains a lot of heterogeneity.

\section{Conflict of Interests}

The author declares that there is no conflict of interests regarding the publication of this paper.

\section{References}

[1] S. Cohen, D. Janicki-Deverts, E. Chen, and K. A. Matthews, "Childhood socioeconomic status and adult health," Annals of the New York Academy of Sciences, vol. 1186, pp. 37-55, 2010.

[2] M. T. Brown, "Early-life characteristics, psychiatric history, and cognition trajectories in later life," The Gerontologist, vol. 50, no. 5, pp. 646-656, 2010.

[3] S. A. Everson-Rose, C. F. Mendes De Leon, J. L. Bienias, R. S. Wilson, and D. A. Evans, "Early life conditions and cognitive functioning in later life," American Journal of Epidemiology, vol. 158, no. 11, pp. 1083-1089, 2003.

[4] S. Fors, C. Lennartsson, and O. Lundberg, "Childhood living conditions, socioeconomic position in adulthood, and 
cognition in later life: exploring the associations," Journal of Gerontology: Social Sciences B, vol. 64, no. 6, pp. 750-757, 2009.

[5] M. N. Haan, A. Zeki Al-Hazzouri, and A. E. Aiello, "Lifespan socioeconomic trajectory, nativity, and cognitive aging in Mexican Americans: the Sacramento Area Latino Study on Aging," The Journals of Gerontology Series B: Psycholocial Sciences and Social Sciences, vol. 66, no. 1, pp. i102-110, 2011.

[6] G. A. Kaplan, G. Turrell, J. W. Lynch, S. A. Everson, E.-L. Helkala, and J. T. Salonen, "Childhood socioeconomic position and cognitive function in adulthood," International Journal of Epidemiology, vol. 30, no. 2, pp. 256-263, 2001.

[7] Y. Luo and L. J. Waite, "The impact of childhood and adult SES on physical, mental, and cognitive well-being in later life," The Journals of Gerontology, Series B: Psychological Sciences and Social Sciences, vol. 60, no. 2, pp. S93-S101, 2005.

[8] J. Lyu and J. A. Burr, "Socioeconomic status across the life course and cognitive function among older adults: an examination of the latency, pathways, and accumulation hypotheses," Journal of Aging and Health, 2015.

[9] C. T. Nguyen, M.-C. Couture, B. E. Alvarado, and M.-V. Zunzunegui, "Life course socioeconomic disadvantage and cognitive function among the elderly population of seven capitals in latin America and the Caribbean," Journal of Aging and Health, vol. 20, no. 3, pp. 347-362, 2008.

[10] C. J. Packard, V. Bezlyak, J. S. McLean et al., "Early life socioeconomic adversity is associated in adult life with chronic inflammation, carotid atherosclerosis, poorer lung function and decreased cognitive performance: a crosssectional, population-based study," BMC Public Health, vol. 11, no. 1, pp. 1-16, 2011.

[11] A. Singh-Manoux, M. Richards, and M. Marmot, "Socioeconomic position across the lifecourse: how does it relate to cognitive function in mid-life?" Annals of Epidemiology, vol. 15, no. 8, pp. 572-578, 2005.

[12] A. Z. Al Hazzouri, M. N. Haan, S. Galea, and A. E. Aiello, "Life-course exposure to early socioeconomic environment, education in relation to late-life cognitive function among older Mexicans and Mexican Americans," Journal of Aging and Health, vol. 23, no. 7, pp. 1027-1049, 2011.

[13] Z. Zhang, D. Gu, and M. D. Hayward, "Early life influences on cognitive impairment among oldest old Chinese," Journals of Gerontology Series B: Psychological Sciences and Social Sciences, vol. 63, no. 1, pp. S25-S33, 2008.

[14] R. Crosnoe and G. H. Elder Jr., "From childhood to the later years: pathways of human development," Research on Aging, vol. 26, no. 6, pp. 623-654, 2004.

[15] D. Kuh, Y. Ben-Shlomo, J. Lynch, J. Hallqvist, and C. Power, "Life course epidemiology," Journal of Epidemiology \& Community Health, vol. 57, no. 10, pp. 778-783, 2003.

[16] Y. Ben-Shlomo and D. Kuh, "A life course approach to chronic disease epidemiology: conceptual models, empirical challenges and interdisciplinary perspectives," International Journal of Epidemiology, vol. 31, no. 2, pp. 285-293, 2002.

[17] H. Graham, "Building an inter-disciplinary science of health inequalities: the example of lifecourse research," Social Science \& Medicine, vol. 55, no. 11, pp. 2005-2016, 2002.

[18] S. Arber and H. Cooper, "Gender differences in health in later life: the new paradox?” Social Science \& Medicine, vol. 48, no. 1, pp. 61-76, 1999.

[19] M. Denton, S. Prus, and V. Walters, "Gender differences in health: a Canadian study of the psychosocial, structural and behavioural determinants of health," Social Science and Medicine, vol. 58, no. 12, pp. 2585-2600, 2004.

[20] A. R. Herzog and R. B. Wallace, "Measures of cognitive functioning in the AHEAD study," The Journals of Gerontology, Series B: Psychological Sciences and Social Sciences, vol. 52, pp. 37-48, 1997.

[21] T. D. Parsons, A. R. Rizzo, C. van der Zaag, J. S. McGee, and J. G. Buckwalter, "Gender differences and cognition among older adults," Aging, Neuropsychology, and Cognition, vol. 12, no. 1, pp. 78-88, 2005.

[22] S. A. Small, Y. Stern, M. Tang, and R. Mayeux, "Selective decline in memory function among healthy elderly," Neurology, vol. 52, no. 7, pp. 1392-1396, 1999.

[23] M. A. Servais, Overview of HRS Public Data Files for CrossSectional and Longitudinal Analysis, Survey Research Center, Institute for Social Research, University of Michigan, Ann Arbor, Mich, USA, 2010.

[24] P. St. Clair, D. Bugliari, N. Campbell et al., RAND HRS Data Documentation, Version L, Labor \& Population Program, RAND Center for the Study of Aging, 2011.

[25] M. B. Ofstedal, G. G. Fisher, and A. R. Herzog, Documentation of Cognitive Functioning Measures in the Health and Retirement Study, Survey Research Center, University of Michigan, Ann Arbor, Mich, USA, 2005.

[26] E. M. Andresen, J. A. Malmgren, W. B. Carter, and D. L. Patrick, "Screening for depression in well older adults: evaluation of a short form of the CES-D," American Journal of Preventive Medicine, vol. 10, no. 2, pp. 77-84, 1994.

[27] USDA, Dietary Guidelines for Americans, 2005, U.S. Government Printing Office, Washington, DC, USA, 2005.

[28] J. D. Singer and J. B. Willett, Applied Longitudinal Data Analysis: Modeling Change and Event Occurrence, Oxford University Press, London, UK, 2003.

[29] L. Fratiglioni, S. Paillard-Borg, and B. Winblad, "An active and socially integrated lifestyle in late life might protect against dementia," The Lancet Neurology, vol. 3, no. 6, pp. 343-353, 2004.

[30] T. E. Seeman, T. M. Lusignolo, M. Albert, and L. Berkman, "Social relationships, social support, and patterns of cognitive aging in healthy, high-functioning older adults: MacArthur Studies of Successful Aging," Health Psychology, vol. 20, no. 4, pp. 243-255, 2001.

[31] N. Weisglas-Kuperus, W. Baerts, M. Smrkovsky, and P. J. J. Sauer, "Effects of biological and social factors on the cognitive development of very low birth weight children," Pediatrics, vol. 92, no. 5, pp. 658-665, 1993.

[32] P. Clarke, G. Fisher, J. House, J. Smith, and D. Weir, Guide to Content of the HRS Psychosocial Leave-Behind Participant Lifestyle Questionnaires: 2004 \& 2006, Survey Research Center, Institute for Social Research, Ann Arbor, Mich, USA, 2007. 


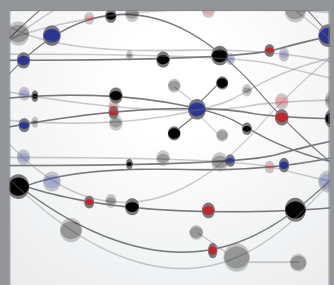

The Scientific World Journal
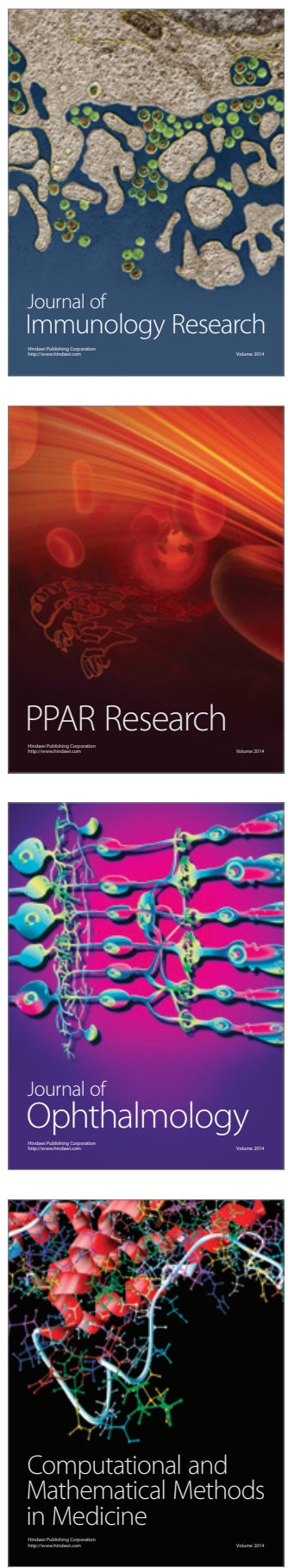

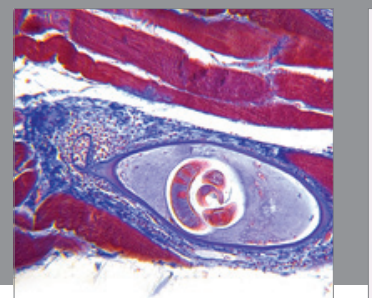

Gastroenterology

Research and Practice
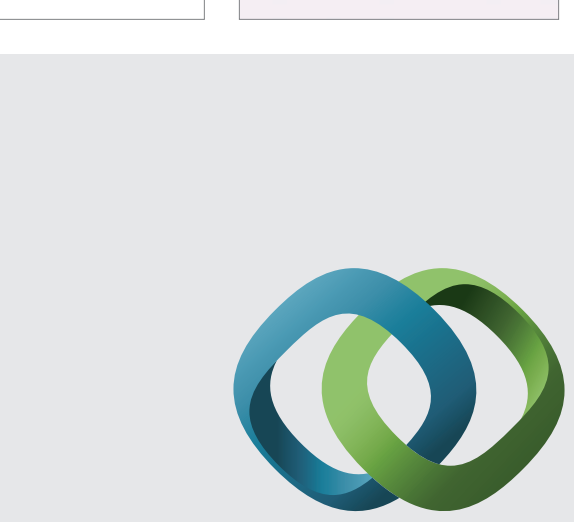

\section{Hindawi}

Submit your manuscripts at

http://www.hindawi.com
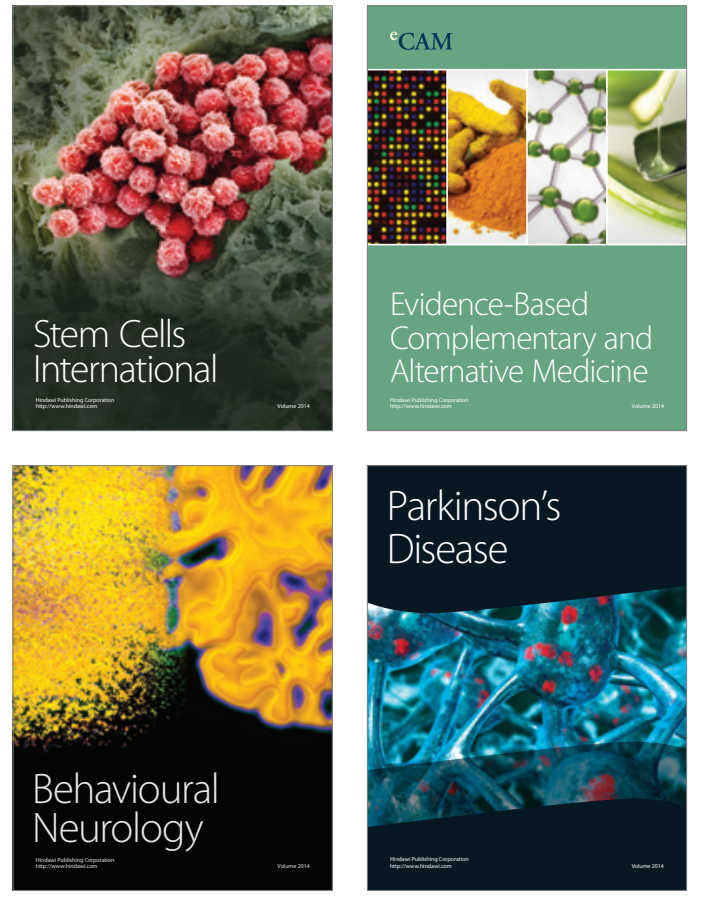
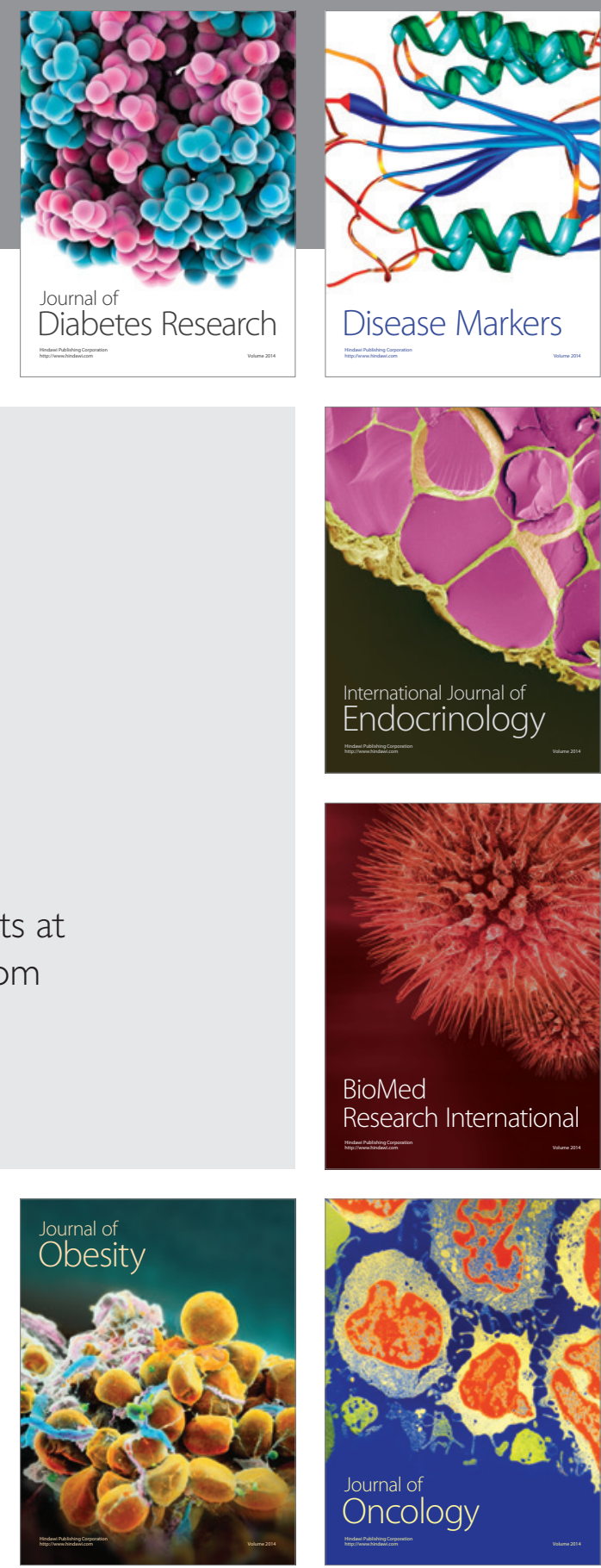

Disease Markers
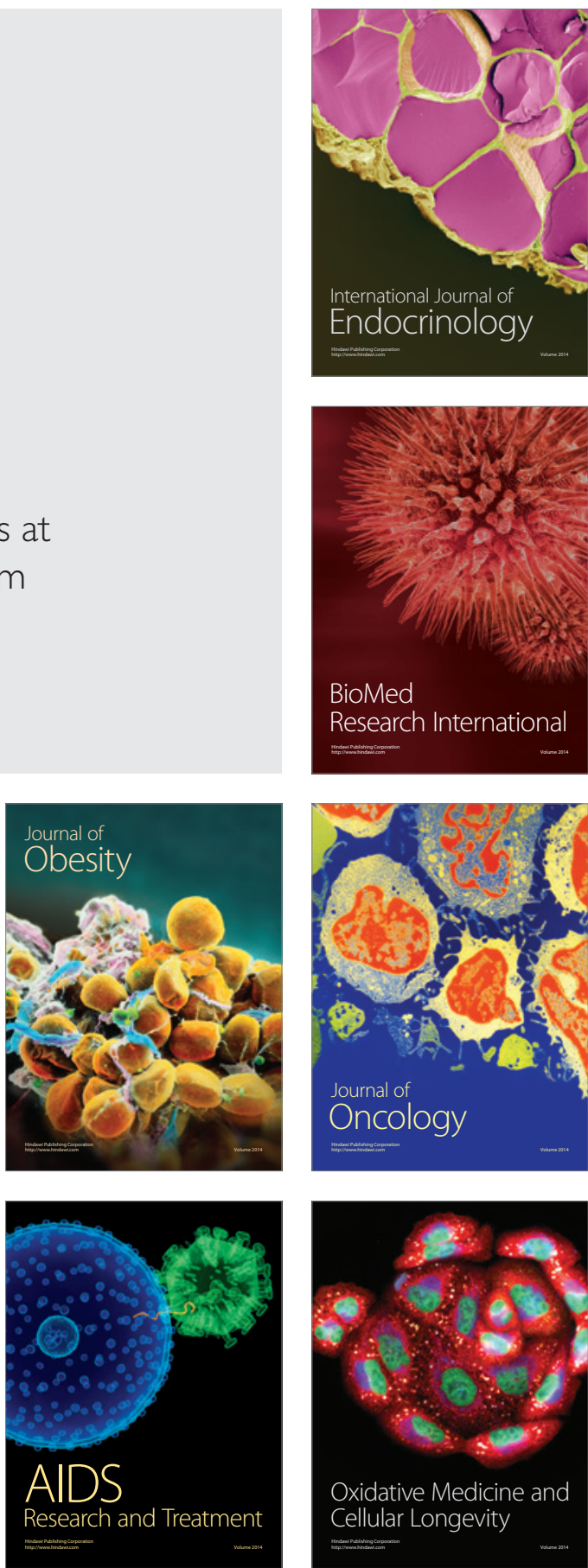